\title{
KUALITAS LAYANAN DAN KEPUASAN SERTA PENGARUHNYA TERHADAP LOYALITAS PELANGGAN
}

\author{
Suwarsito ${ }^{1}$, Sabeli Aliya ${ }^{2}$ \\ Universitas Bina Sarana Informatika ${ }^{1}$, Universitas Bina Darma ${ }^{2}$ \\ suwarsito.swr@bsi.ac.id ${ }^{1}$, sably@ binadarma.ac.id ${ }^{2}$
}

\begin{abstract}
:
This research aims to identify and analyze the effect of the service quality and satisfaction variables toward customer loyalty. Method of data collection in this research is using the survey method with questionnaires. Population in this research is the customers of Indosat Unlimited in Depok. Based on the results of the analysis, it indicates that the service quality significantly influences the customer loyalty, shown by the t significant value of 0.000 smaller that $\alpha 0.05$ with the regression coefficient of 2.537. service quality has a significant effect on the customer loyalty indicated by the t significant value 0.000 less than $\alpha=0.05$. service quality and satisfaction significantly influence the customer loyalty shown by $F$ significant value of 0.000 smaller than $\alpha=0.05$ and are able contribute to the customer loyalty variables of 0.504 or $51.7 \%$. the remaining $48.3 \%$ is influenced by other variables that are not examined in this research.
\end{abstract}

\begin{abstract}
ABSTRAK
Penelitian ini bertujuan untuk menjelaskan pengaruh variabel kualitas layanan dan kepuasan terhadap loyalitas pelanggan Indosat Unlimited di Cimanggis. Metode pengumpulan data dalam penelitian ini menggunakan metode survey melalui kuesioner. Berdasarkan hasil dari analisa penelitian ini, mengindikasikan bahwa kualitas layanan secara signifikan berpengaruh terhadap loyalitas pelanggan, ditunjukan dari nilai signifikan si uji $\mathrm{t}=0.000$ lebih kecil dari $\alpha=0.05$ dengan koefisien regresi $=2.537$. kualitas layanan secara signifikan berpengaruh terhadap loyalitas pelanggan ditunjukan dengan nilai signifikansi uji $\mathrm{t}=0.000$ lebih kecil dari $\alpha=0,05$. Kualitas layanan dan kepuasan secara simultan berpengaruh signifikan terhadap loyalitas pelanggan, ditunjukan dari nilai signifikansi uji $\mathrm{F}=0,000$ lebih kecil dari $\alpha=0.05$ dan mampu memiliki kontribusi terhadap variabel loyalitas pelanggan sebesar 0.504 atau $51.7 \%$. sisanya sebesar $48.3 \%$ dipengaruhi oleh variable lain yang tidak dianalisa dalam penelitian ini.
\end{abstract}




\section{Latar Belakang}

Di zaman modern seperti saat ini internet telah menjadi hal yang sangat dibutuhkan dalam kehidupan. Hampir setiap hari kita terhubung dengan jaringan internet. Perkembangan era digital yang pesat saat ini, sangat membantu masyarakat dunia memberikan kemudahan layanan dan cakupan tanpa batas. Seiring pesatnya perkembangan teknologi, membuat pengguna internet di dunia pun ikut melambung tinggi. Terlebih lagi untuk generasi millennials, baik itu untuk kehidupan sehari-hari maupun pada kegiatan bisnis tidak bisa lepas dari yang namanya teknologi internet.

Menurut Sibero (2011), Internet
yaitu Inter-connected Network yang
merupakan sebuah jaringan komputer yang saling menghubungkan antar komputer secara global. Internet dapat bekerja sama seperti jaringan komputer, dan juga jaringan komputer lokal maupun jaringan komputer area yang lebih luas, dan interet menggunakan sebuah protocol komunikasi yang sama yaitu TCP/IP (Transmission Control Protokol/Control Protokol)

Dengan meningkatnya penggunaan internet, maka banyak pula provider penyedia layanan internet yang bermunculan yang menyuguhkan berbagai jenis layanan internet sesuai dengan kebutuhan pelanggan.

Dengan semakin banyak bermunculan provider penyedia layanan internet di Indonesia, maka semakin ketat juga persaingan merebut minat dan loyalitas pelanggan. Berbagai macam cara banyak dilakukan para provider untuk dapat memenuhi kebutuhan, kepuasan serta loyalitas pelanggan mereka.

Indosat sebagai salah satu penyedia layanan internet di Indonesia juga terus meningkatkan layanan mereka. Salah satunya dengan menggunakan adanya paket Indosat Unlimited. Indosat Unlimited memberikan paket layanan dengan harga yang terjangkau dengan paket kecepatan yang bisa dipilih sesuai kebutuhan pelanggan.

Namun dengan peningkatan layanan tersebut, apakah sudah cukup mampu mempertahankan loyalitas pelanggan mereka atau bahkan mampu meningkatkan jumlah pelanggan mereka. Pertanyaan inilah yang kemudian mendasari peneliti untuk melihat sejauh mana kualitas layanan dan kepuasan mampu mempengaruhi loyalitas pelanggan Indosat Unlimited.

\section{Tujuan Penelitian}

1. Untuk mengetahui pengaruh kualitas layanan dan kepuasan secara bersama sama terhadap loyalitas pelanggan Indosat Unlimited.

2. Untuk mengetahui pengaruh parsial kualitas layanan terhadap loyalitas pelanggan Indosat Unlimited.

3. Untuk mengetahui pengaruh parsial kepuasan terhadap loyalitas pelanggan Indosat Unlimited.

\section{TINJAUAN PUSTAKA}

\section{Kualitas Layanan}

Menurut Kotler (2011) kualitas harus dimulai dari kebutuhan pelanggan dan berakhir pada persepsi pelanggan. Berarti bahwa citra kualitas yang baik bukan dilihat dari persepsi pihak perusahaan atau penyedia jasa, melainkan berdasar persepsi para pelanggan.

Menurut Supranto (2011), kualitas pelayanan adalah sebuah kata yang bagi penyedia jasa merupakan sesuatu yang harus dikerjakan dengan baik. Sedangkan kualitas pelayanan menurut Gronroos (dalam Ratminto, 2008) adalah suatu aktivitas atau 
serangkaian aktivitas yang bersifat tidak kasat mata yang terjadi sebagai akibat adanya interaksi antara konsumen dengan karyawan atau hal-hal lain yang disediakan oleh perusahaan pemberi pelayanan yang dimaksud untuk memecahkan permasalahan konsumen/pelanggan.

Ketika produk berwujud tidak dapat dengan mudah dibedakan, kunci utama keberhasilan kompetitifnya terletak pada penambahan nilai jasa pelayanan yang baik dan peningkatan kualitas produk. Pembeda jasa pelayanan yang dapat dinikmati oleh konsumen ialah kemudahan pemesanan, pengiriman, instalasi atau pemasangan, pelatihan konsumen, konsultasi konsumen, dan perawatan dan perbaikan (Mahmud Machfoedz, 2010).

Dimensi kualitas pelayanan (SERVQUAL) oleh Parasuraman (dalam Lupiyoadi, 2014) dibagi menjadi lima dimensi SERVQUAL diantaranya adalah:

Tangibles (Bukti Fisik).

Kemampuan suatu perusahaan dalam menunjukkan eksistensinya kepada pihak eksternal. Penampilan dan kemampuan sarana dan prasaranan fisik perusahaan dan keadaan lingkungan sekitarnya adalah bukti nyata dari pelayanan yang diberikan oleh pemberi jasa. Yang meliputi fasilitas fisik (gedung, gudang, dan lain sebagainya), perlengkapan dan peralatan yang ipergunakan (teknologi), serta penampilan pegawainya.

Reliability (Kehandalan).

Kemampuan perusahaan untuk memberikan pelayanan sesuai yang dijanjikan secara akurat dan terpercaya. Kinerja harus sesuai dengan harapan pelanggan yang berarti ketepatan waktu, pelayanan yang sama untuk semua pelanggan tanpa kesalahan, sikap yang simpatik, dan dengan akurasi yang tinggi.
Responsiveness (Ketanggapan).

Kemauan untuk membantu dan memberian pelayanan yang cepat (responsif) dan tepat kepada pelanggan, dengan penyampaian informasi yang jelas.

Assurance (Jaminan dan Kepastian).

Pengetahuan, kesopansantunan, dan kemampuan para pegawai perusahaan untuk menumbuhkan rasa percaya para pelanggan kepada perusahaan. Terdiri dari bebeapa komponen antara lain komunikasi, kredibilitas, keamanan, kompetensi, dan sopan santun.

Emphaty (Empati).

Memberikan perhatian yang tulus dan bersifat individual atau pribadi yang diberikannkepada para pelanggan dengan berupaya memahami keinginan konsumen. Dimana suatu perusahaan diharapkan memiliki pengertian dan pengetahuan tentang pelanggan, memahami kebutuhan pelanggan secara spesifik, serta memiliki waktu untuk pengoperasian yang nyaman bagi pelanggan.

\section{Kepuasan}

Kepuasan atau satisfaction berasal dari bahasa latin "satis" (artinya cukup baik, memadai) dan "facio"(melakukan atau membuat). Secara sederhana kepuasan dapat diartikan sebagai upaya pemenuhan sesuatu atau membuat sesuatu memadai. Namun, ditinjau dari perspektif perilaku konsumen, istilah kepuasan konsumen lantas menjadi sesuatu yang kompleks. Menurut Kotler dan Amstrong (2016) kepuasan konsumen adalah "the extent to which a product's perceived performance matches a buyer's expectation". Kepuasan konsumen adalah tingkat dimana suatu pencapaian performa dari sebuah produk yang diterima oleh konsumen sama dengan ekspektasi konsumen itu sendiri. 
Sedangkan menurut Irawan (2008), kepuasan konsumen adalah hasil dari akumulasi dari konsumen atau pelanggan dalam menggunakan produk dan pelayanan (jasa). Konsumen puas kalau setelah membeli produk tersebut, ternyata kualitas produknya baik. Oleh karena itu, setiap transaksi atau pengalaman baru, akan memberikan pengaruh terhadap kepuasan konsumen.

Konsumen yang puas adalah konsumen yang akan berbagi rasa dan pengalaman nya dengan konsumen lain. Pandangan terhadap kepuasan konsumen sangat bervariasi, keragaman itu akan memberikan pembaca pemahaman yang lebih luas. Tidak ada satupun ukuran tunggal terbaik mengenai kepuasan konsumen yang disepakati secara universal. Meskipun demikian, di tengah beragamnya cara mengukur kepuasan konsumen, ada beberapa kesamaan konsep inti mengenai objek pengukuran sebagai berikut:

a. Kepuasan Konsumen Keseluruhan (Overall Customer Satisfaction) Cara paling sederhana untuk mengukur kepuasan konsumen adalah langsung menanyakan kepada konsumen seberapa puas mereka dengan produk atau jasa spesifik tertentu. Biasanya, ada dua bagian dalam proses pengukurannya. Pertama,mengukur tingkat kepuasan konsumen terhadap produk atau jasa perusahaan bersangkutan. Kedua, menilai dan membandingkan dengan tingkat kepuasan konsumen keseluruhan terhadap produk atau jasa para pesaing.

b. Konfirmasi Harapan (Confirmation Of Expectations)Dalam konsep ini, kepuasan konsumen tidak diukur langsung, namun disimpulkan berdasarkan kesesuaian/ ketidaksesuaian antara harapan konsumen dengan kinerja aktual jasa atau produk perusahaan pada sejumlah atribut atau dimensi penting

c. Kesediaan untuk merekomendasikan ( willingness to recommend) dalam kasus pembelian ulangnya relatif lama atau bahkan hanya terjadi satu kali pembelian, kesediaan konsumen untuk merekomendasikan kepada teman atau kelurganya menjadi ukuran yang penting untuk dianalisis dan ditindak lanjuti.

Menurut Kotler bahwa untuk menentukan tingkat kepuasan konsumen, terdapat lima indicator yang harus diperhatikan oleh perusahaan yaitu:

a. Kualitas Layanan

Konsumen akan merasa puas bila mereka mendapatkan pelayanan yang baik atau yang sesuai dengan yang diharapkan.

b. Kualitas Produk

Konsumen akan merasa puas bila hasil evaluasi mereka menunjukkan bahwa produk yang mereka gunakan berkualitas.

c. Emosional

Konsumen akan merasa bangga dan mendapat keyakinan bahwa orang lain akan kagum dengannya bila menggunakan produk dengan merek tertentu sehingga menimbulkan kepuasan yang lebih tinggi. Kepuasan yang diperoleh bukan karena kualitas dari produk tetapi nilai sosial atau self-esteem yang membuat konsumen menjadi puas terhadap merek tertentu.

d. Harga

Produk yang mempunyai kualitas yang sama tetapi menetapkan harga yang Relatif murah akan memberikan nilai yang Relatif tinggi kepada konsumen sehingga menimbulkan kepuasan. 
e. Biaya dan Kemudahan

Konsumen yang tidak perlu mengeluarkan biaya tambahan atau tidak perlu membuang waktu untuk mendapatkan suatu produk atau jasa cenderung puas terhadap produk atau jasa itu. Berdasarkan pendapat diatas dapat disimpulkan bahwa dalam menentukan tingkat kepuasan kepuasan konsumen meliputi indikator kualitas produk, kualitas layanan, emosional, harga dan biaya dan kemudahan

\section{Loyalitas Pelanggan}

Hurriyati (2014) menyatakan bahwa loyalitas pelanggan (costomer loyalty) merupakan dorongan yang sangat penting untuk menciptakan penjualan. Menurut Engel (2012), loyalitas juga didefinisikan sebagai komitmen mendalam untuk membeli ulang atau mengulang pola prefensi produk atau layanan di masa yang akan datang, yang menyebabkan pembelian berulang merek yang sama atau suatu set merek yang sama, walaupun ada keterlibatan faktor situasional dan upaya-upaya pemasaran yang berpotensi menyebabkan perilaku berpindah merek.

Para pelanggan yang loyal selalu menolak apabila ditawari produk atau jasa dari perusahaan lain (pesaing). Mereka sudah memiliki kecintaan tersendiri terhadap produk atau jasa yang telah digunakan.

Dick \& Basu dalam Tjiptono (2010) menjelaskan loyalitas mencangkup dua komponen yang penting, yaitu berupa loyalitas sebagai perilaku dan loyalitas sebagai sikap. Kombinasi dari dua komponen tersebut akan menghasilkan empat jenis situasi kemungkinan loyalitas, yaitu: no loyalty, spurious loyalty, latent loyalty, dan loyalty”. Tjiptono (2011) menjelaskan empat jenis situasi kemungkinan loyalitas dari Dick \& Basu, sebagai berikut:

\section{No Loyalty}

Hal ini dapat terjadi bila sikap dan perilaku pembelian ulang pelanggan samasama lemah, maka loyalitas tidak terbentuk.

\section{Spurious Loyalty}

Keadaan seperti ini ditandai dengan pengaruh non sikap terhadap perilaku, seperti norma subjektif dan faktor situasional. Situasi semacam ini dapat dikatakan pula inertia, dimana konsumen sulit membedakan berbagai merk dalam kategori produk dengan tingkat keterlibatan rendah. Sehingga pembelian ulang di lakukan atas dasar pertimbangan situasional, seperti familiarity (dikarenakan penempatan produk yang strategis pada rak pajangan, lokasi outlet di pusat perbelanjaan)

\section{Latent Loyalty}

Situsi latent loyalty tercermin bila sikap yang kuat disertai pola pembelian ulang yang lemah. Situasi yang menjadi perhatian besar para pemasar ini disebabkan pengaruh faktor-faktor non sikap yang sama kuat atau bahkan cenderung lebih kuat daripada faktor sikap dalam menentukan pembelian ulang.

\section{Loyalty}

Situasi ini merupakan situasi yang ideal yang paling di harapkan para pemasar. Di mana konsumen bersikap positif terhadap produk atau produsen dan disertai pola pembelian ulang yang konsisten.

\section{METODE PENELITIAN}

Jenis penelitian yang digunakan dalam penelitian ini adalah explanatory research atau penelitian penjelasan dengan pendekatan kuantitatif. Jumlah sampel yang digunakan dalam penelitian ini sebanyak 52 responden pelanggan layanan Indosat 
Unlimited di Cimanggis Depok. Teknik pengambilan sampel mengggunakan teknik random sampling yaitu sampel diambil secara acak.

Teknik analisis data yang digunakan adalah: a. Analisis deskriptif

Analisis deskriptif diperlukan pada variable-variabel penelitian. Berdasarkan variabel tersebut, analisis dapat dilakukan untuk mendapatkan informasi mengenai banyak hal. (Umar, 2011)

b. analisis regresi linier berganda

Analisa model persamaan linier berganda digunakan untuk meregresikan secara simultan antara variabel bebas dengan variabel terikat.

Dalam penelitian ini model regresi yang digunakan yaitu:

$\mathrm{Y}=\mathrm{a}+\mathrm{b} 1 \mathrm{X} 1+\mathrm{b} 2 \mathrm{X} 2+\mathrm{e}$

Keterangan:

$\mathrm{Y}=$ Variabel terikat ( Loyalitas pelanggan)

$\mathrm{X} 1=$ Variabel bebas (Kualitas layanan)

$\mathrm{X} 2=$ Variabel bebas (Kepuasan)

$\mathrm{a}=$ konstanta

$\mathrm{b} 1, \mathrm{~b} 2=$ koefisien regresi

c. Uji F

untuk melakukan pengujian pengaruh dari variabel-variabel bebas secara simultan terhadap variabel terikat.

d. Uji t

Uji $t$ dilakukan untuk menguji signifikansi masing-masing variabel bebas secara parsial

\section{HASIL DAN PEMBAHASAN}

a. Hasil

1. Uji Linearitas

Uji lineritas dilakukan untuk menentukan teknik dalam analisis regresi apakah variabel bebas $\left(\mathrm{X}_{1}\right.$ dan $\mathrm{X}_{2}$ ) dan variabel terikat $(\mathrm{Y})$ terbentuk linear. Uji linearitas ini menggunakan perhitungan SPSS 20.0

a. Linaeritas Regresi pengaruh variable $X_{1}$ atas $Y$

Hasil uji linearitas regresi antara kualitas layanan dengan loyalitas pelanggan., perhitungan SPSS 20.0 sebagai berikut:

Tabel 1

Hasil Pengujian Linearitas

Regresi Variabel $\mathrm{Y}$ atas $\mathrm{X}_{1}$

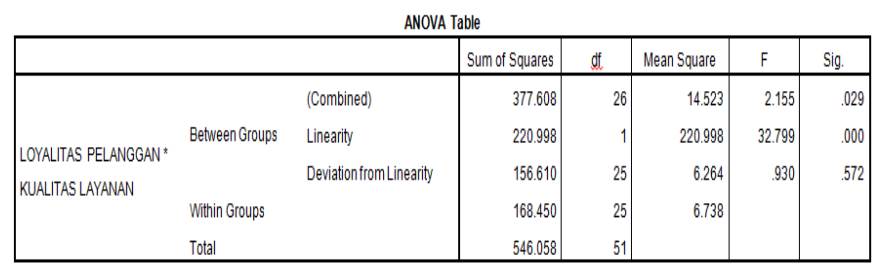

Berdasarkan hasil perhitungan di atas diperoleh hasil perhitungan Deviation from Linearity dengan $\mathrm{Fo}=$ 0.90 dan Sig. $=.572>0,05$. Hal ini memiliki pengertian bahwa variabel kualitas layanan dengan loyalitas pelanggan mempunyai mempunyai hubungan yang linear.

b. Linaeritas Regresi pengaruh variable $\mathrm{X}_{2}$ atas $\mathrm{Y}$

Hasil uji linearitas regresi antara Kepuasan dengan Loyalitas pelanggan, perhitungan SPSS 20.0 sebagai berikut: 
Tabel 2

Hasil Pengujian Linearitas Regresi Variabel $\mathrm{Y}$ atas $\mathrm{X}_{2}$

\begin{tabular}{|c|c|c|c|c|c|c|c|}
\hline \multicolumn{8}{|c|}{ ANOVA Table } \\
\hline & & & Sum of Squares & of & Mean Square & $\mathrm{F}$ & Sig. \\
\hline & & (Combined) & 315.941 & 28 & 11284 & 1.128 & 388 \\
\hline & Between Groups & Linearity & 231.963 & 1 & 231.963 & 23.185 & .000 \\
\hline KEPUASAN & & Deviationfrom Linearity & 83.978 & 27 & 3.110 & 311 & 998 \\
\hline & Witin Groups & & 230.117 & 23 & 10.005 & & \\
\hline & Total & & 546.058 & 51 & & & \\
\hline
\end{tabular}

Berdasarkan hasil perhiungan di atas diperoleh hasil Deviation from Linearity dengan $\mathrm{F}=0.311$ dan Sig. $=0,998>0,05$. Hal ini memiliki pengertian bahwa variabel kepuasan dengan loyalitas pelanggan mempunyai mempunyai hubungan yang linear.

\section{b. Pembahasan}

Hasil perhitungan dan pengujian bisa dilihat pada tabel di bawah ini:

Tabel Hasil Perhitungan Pengujian Koefisien Korelasi Ganda Variabel $\mathrm{X}_{1}$ dan $\mathrm{X}_{2}$ terhadap Y

\begin{tabular}{|l|l|r|r|r|}
\hline Model & \multicolumn{1}{|c|}{ Model Summary } & R Square & $\begin{array}{c}\text { Adjusted } R \\
\text { Square }\end{array}$ & $\begin{array}{c}\text { Std. Error of the } \\
\text { Estimate }\end{array}$ \\
\hline 1 & $.719^{\mathrm{a}}$ & .517 & .498 & 2.319 \\
\hline
\end{tabular}

a. Predictors: (Constant), KEPUASAN, KUALITAS LAYANAN

b. DependentVariable:LOYALITAS PELANGGAN

Tabel Hasil Perhitungan Pengujian Signifikansi Koefisien Regresi Variabel $\mathrm{X}_{1}$ dan $\mathrm{X}_{2}$ terhadap $\mathrm{Y}$

\begin{tabular}{|c|c|c|c|c|c|c|}
\hline \multicolumn{7}{|c|}{ ANQVA } \\
\hline & & Sum of Squares & $\mathrm{df}$ & Mean Square & $\mathrm{F}$ & Sig. \\
\hline \multirow{3}{*}{1} & Regression & 282.471 & 2 & 141.236 & 26.255 & $.000^{\circ}$ \\
\hline & Residual & 263.586 & 49 & 5.379 & & \\
\hline & Total & 546.058 & 51 & & & \\
\hline
\end{tabular}

a. DependentVariable:LOYALITAS PELANGGAN

b. Predictors: (Constant), KEPUASAN, KUALITAS LAYANAN

Tabel Hasil Perhitungan Persamaan Regresi Ganda Variabel $\mathrm{X}_{1}$ dan $\mathrm{X}_{2}$ terhadap $\mathrm{Y}$

\begin{tabular}{|c|c|c|c|c|c|c|}
\hline \multicolumn{7}{|c|}{ Coefficients $\mathrm{s}^{\mathrm{a}}$} \\
\hline \multirow[t]{2}{*}{ Mode } & & \multicolumn{2}{|c|}{ Unstandardized Coefficients } & \multirow{2}{*}{$\begin{array}{c}\text { Standardized } \\
\text { Coefficients } \\
\text { Beta } \\
\end{array}$} & \multirow[t]{2}{*}{$t$} & \multirow[t]{2}{*}{ Sig. } \\
\hline & & $B$ & Std. Error & & & \\
\hline \multirow{3}{*}{1} & (Constant) & 61.059 & 1.951 & & 31.299 & .000 \\
\hline & KUALITAS LAYANAN & .116 & .038 & .382 & 3.064 & .004 \\
\hline & KEPUASAN & .150 & .044 & .421 & 3.380 & .001 \\
\hline
\end{tabular}

1. Pengaruh kualitas layanan (X1) dan kepuasan (X2) secara bersama-sama terhadap loyalitas pelanggan .(Y)

Hipotesis yang diuji:

$$
\begin{aligned}
& H_{0}: \beta_{y 1}=\beta_{y 2}=0 \\
& H_{1}: \beta_{y 1} \neq 0, \text { atau } \beta_{y 2} \neq 0
\end{aligned}
$$

Artinya:

$\mathrm{H}_{0} \quad$ : tidak terdapat pengaruh kualitas layanan dan kepuasan secara bersamasama terhadap loyalitas pelanggan .

$\mathrm{H}_{1} \quad$ : terdapat pengaruh kualitas layanan dan kepuasan secara bersama-sama terhadap loyalitas pelanggan .

Dari tabel diatas terdapat pengaruh yang signifikan kualitas layanan dan kepuasan secara bersama-sama terhadap loyalitas pelanggan. Hal ini dibuktikan dengan perolehan nilai $\mathrm{F}=26.255$ dan Sig. 0,000<0,05

Sementara itu, persamaan garis regresi ganda dapat dinyatakan dengan $\widehat{Y}=61.059+0,116 \mathrm{X} 1$ $+0,150$ X2. Hal ini memiliki pengertian bahwa kenaikan satu skor variable kualitas layanan dan kepuasan memberikan kontribusi sebesar 0,116 oleh X1 dan 0,150 oleh X2 terhadap variable loyalitas pelanggan. Dari tabel di atas juga dapat menjelaskan bahwa secara 
bersama-sama variable kualitas layanan dan kepuasan memberikan kontribusi sebesar $51.7 \%$ terhadap variable loyalitas pelanggan.

1. Pengaruh kualitas layanan $\left(\mathrm{X}_{1}\right)$ terhadap loyalitas pelanggan .(Y)

Hipotesis yang diuji:

$$
\begin{aligned}
& H_{0}: \beta_{y 1}=0 \\
& H_{1}: \beta_{y 1} \neq 0
\end{aligned}
$$

Artinya:

$\mathrm{H}_{0} \quad$ : tidak terdapat pengaruh kualitas layanan terhadap loyalitas pelanggan .

$\mathrm{H}_{1} \quad$ :terdapat pengaruh kualitas layanan terhadap loyalitas pelanggan .

Dari tabel di atas. dapat dinyatakan bahwa terdapat pengaruh yang signifikan kualitas layanan terhadap loyalitas pelanggan. Hal ini dibuktikan dengan perolehan nilai Sig. 0,000<0,05.

Adapun kontribusi variabel kualitas layanan terhadap Loyalitas pelanggan . dapat dinyatakan dengan rumus:

$$
\mathrm{KD}=\text { Nilai } \beta_{x 1 y} \mathrm{x} \text { Nilai }
$$

Korelasi Pasialnya $\left(r_{x 1 y}\right) \times 100 \%$

$$
\mathrm{KD}=0,636 \times 0,382 \times 100 \%=
$$
$24,29 \%$

Dari hasil perhitungan di atas dapat dinyatakan bahwa kontribusi kualitas layanan dalam meningkatkan loyalitas pelanggan .sebesar $24,29 \%$

2. Pengaruh Kepuasan (X2) terhadap Loyalitas pelanggan (Y)

Hipotesis yang diuji:

$$
H_{0}: \beta_{y 1}=0
$$

$$
H_{1}: \beta_{y 1} \neq 0
$$

Artinya:

$\mathrm{H}_{0}$ : tidak terdapat pengaruh kualitas layanan terhadap loyalitas pelanggan .

$\mathrm{H}_{1}$ :terdapat pengaruh kualitas layanan terhadap loyalitas pelanggan .

Dari tabel di atas dapat dinyatakan bahwa terdapat pengaruh yang signifikan kepuasan terhadap loyalitas pelanggan. Hal ini dibuktikan dengan perolehan nilai dan Sig. 0,001<0,05.

Adapun kontribusi variabel kepuasan terhadap loyalitas pelanggan .dapat dinyatakan dengan rumus:

$\mathrm{KD}=$ Nilai $\beta_{x 2 y} \mathrm{x}$ Nilai Korelasi Pasialnya $\left(r_{x 2 y}\right) \times 100 \%$

$$
\mathrm{KD}=0,652 \times 0,421 \times 100 \%=
$$
$29,23 \%$

Dari hasil perhitungan di atas dapat dinyatakan bahwa kontribusi kualitas layanan dalam meningkatkan loyalitas pelanggan .sebesar $27,45 \%$.

\section{KESIMPULAN DAN SARAN}

\section{Kesimpulan}

1. Kualitas layanan berpengaruh signifikan terhadap loyalitas pelanggan

2. Kepuasan berpengaruh signifikan terhadap loyalitas pelanggan.

3. Kualitas layanan dan kepuasan secara simultan berpengaruh signifikan terhadap loyalitas pelanggan. 


\section{Saran}

1. Provider perlu lebih meningkatkan kualitas layanan agar mereka dapat lebih meningkatkan loyalitas pelanggan, Misalnya dengan cara melakukan perawatan jaringan rutin atau dengan menayakan merespon dengan cepat keluhan pelanggan Dengan demikian.

2. Mempertahankan atau meningkatkan kecepatan transfer data agar kepuasan pelanggan tetap terjaga dan tidak menaikan harga paket tanpa adanya peningkatan layanan.

3. Bagi peneliti selanjutnya, diharapkan dapat melakukan pengembangan penelitian dengan menggunakan variable bebas lain sehingga dapat memberikan pengaruh lebih baik lagi terhadap loyalitas pelanggan.

\section{DAFTAR PUSTAKA}

Dick, A.S dan Basu, K., 1994, "Customer Loyalty : Toward an Integrated Conceptual Framework", Journal of The Academy Marketing Science, Vol.22, p.99-113.

Engel, J.F, Blackwell, Rd dan Miniard. 2012. Perilaku Konsumen. Tangerang : Binarupa Aksara

Hurriyati, Ratih. 2014. Bauran Pemasaran dan Loyalitas Konsumen. Bandung: Alfabeta

Irawan, Basu Swasta. 2008 Manajemen Pemasaran Modern, Yogyakarta: Liberty
Kotler, Philip and Kevin Lane Keller, 2011. Manajemen Pemasaran, Edisi 13 Jilid 1 dan 2, Alih Bahasa : Bob Sabran, Erlangga, Jakarta.

Kotler, P. And Amstrong, G. 2016 Principles Of Marketing,Global Edition, 14 edition, USA: Prentice Hall

Lupiyoadi, Rambat. 2014. Manajemen Pemasaran Jasa. Edisi 3 Jakarta : PT. Salemba Empat.

Mahmud Machfoedz. 2010. Pengantar Pemasaran Modern. Yogyakarta: Cakra Ilmu

Ratminto dan Winarsih Atik Septi. (2008). Manajemen Pelayanan publik. Yogyakarta: Penerbit Pustaka Pelajar

Sibero, 2011, Kitab Suci Web Programming, MediaKom, Yogyakarta

Stanton, J. William. 2012, Prinsip Pemasaran, alih bahasa : Yohanes Lamarto Jakarta : Erlangga,

Supranto. 2011 Pengukuran Tingkat Pelanggan, cetakan ke empat Jakarta: Rineka Cipta.

Tjiptono, Fandy. 2010. Service Management: Mewujudkan Layanan Prima. Yogyakarta: Andi Offset.

Tjiptono, Fandy. 2011. Prinsip-Prinsip Total Quality Service, Yogyakarta: Andi Offset

Umar, Husein. 2011. Metode Penelitian Untuk Skripsi dan Tesis Bisnis, Edisi kedua. Jakarta: Raja Grafindo Persada. 